\title{
Saha Türklerinin Kıs Debeliye Oloñxosunda Yer Alan Kahramanlar ve Yer Adları Üzerine Bir İnceleme
}

An Analysis on the Heroes and Place Names Mentioned in Kıs Debeliye Oloñxo of Sakha Turks

\section{Araş. Gör. Dr. Doğan Çolak ${ }^{1}$}

Başvuru Tarihi: 23.12.2019

Kabul Tarihi: 24.06.2020

Makale Türü: Araştırma Makalesi

Öz

Saha Türkleri çok zengin bir destan geleneğine sahiptir ve bu geleneği günümüzde de yaşatmaya çalışmaktadırlar. Günlük yaşamda dahi destanlar ve destanlarla ilgili unsurları görmek mümkündür. Oloñxo olarak adlandırılan destanların sayısı tam olarak tespit edilmemekle birlikte oldukça fazla olduğu söylenebilir. Bu destanlardan biri de başkahramanı kadın olan Kııs Debeliye destanıdır. Kıns Debeliye destanı, Saha Türklerinin destan geleneğinin hem ahlaki hem estetik değerlerini içinde barındıran bir destandır. Kadın başkahraman Kııs Debeliye, Sahalar için önemli bir figürdür.

Kııs Debeliye, esasında Yukarı Dünya'da yaşıyor olmasına rağmen, destanda Orta Dünya'ya sürgün edilir ve orada yaşamını sürdürür. Orta Dünya halkının başı sıkıştığında yardımına başvurduğu önemli bir kahramandır. Destandaki diğer bir önemli kahraman ise Çugdaan Buxatır'dır. Ülkesi, kötü başkahraman olan Saraxana Kü̈̈kenńik'in evlatları tarafından işgal edilip yağmalanınca önce kendi başına ona karşı savaşır, başarılı olamayınca Kııs Debeliye’nin yardımına başvurur.

Incelenen metinde yer alan altmış bir kahramandan on beşi insanoğlu olup geriye kalan kırk altısı ise mitolojik özellik gösteren kahramanlardır. Yirmi beş yer adından da biri gerçek dünyayla ilişkili olup kalan yirmi dördü mitolojik yer özelliği taşımaktadır.

Anahtar Kelimeler: Saha Türkleri, Destan (Oloñxo), Kııs Debeliye Buxatıır, Kahraman, Yer Adlari

\footnotetext{
${ }^{1}$ Nevşehir Hacı Bektaş Veli Üniversitesi, Fen-Edebiyat Fakültesi, Çağdaş Türk Lehçeleri ve Edebiyatları Bölümü, dcolak@nevsehir.edu.tr / dogan_colak@hotmail.com, ORCID: 0000-0003-3331-7496
} 


\section{Abstract}

Sakha Turks have a very rich tradition of epic and they have been trying to keep this tradition alive today. It is even possible to see epics and elements related to epics in everyday life. Although the number of epics called oloñxo is not exactly determined, it can be said to be quite a lot. One of these epics is the epic of Kuns Debeliye of which protagonist is female. Kuns Debeliye is an epic that embodies both moral and aesthetic values of the epic tradition of Sakha Turks. The heroine, Kuns Debeliye, is an important figure for Sakhas.

Although Kus Debeliye lives in the Upper World, she is exiled to the Middle Earth in the epic and continues to live there. She is an important heroine whom the people of Middle-earth ask for help when they are in trouble. Another important hero in the epic is Çugdaan Buxatur. When his country is occupied and plundered by the sons of the antagonist, Sarashan Kuukenikik, he fights against him alone but when he fails, he asks for the help of Kus Debeliye.

Fifteen of the sixty personas in the studied text are human beings, and the remaining forty-six are heroes with mythological features. Only one out of twenty-five place names mentioned in the text is related to the real world, and the remaining twenty-four are mythological places.

Keywords: Sakha Turks, Epic (Oloñxo), Kııs Debeliye Buxatır, Hero/Heroine, Place Names

\section{Giriş}

Günümüzde destan geleneklerini sürdüren Türk boylarından olan Sahaların bu gelenekte zengin bir birikime sahip oldukları görülmektedir. Sahalar, bu birikime sahip çıkmak adına ciddi bir bilinç ortaya koymaktadırlar. Destanlara verilen önemin göstergesi olarak, Saha Yeri'nde sadece destanların sahnelendiği, dünyada eşine az rastlanan oloñxo tiyatrosu örnek gösterilebilir. Bunun yanı sıra “Oloñxo Bölgesi” projesi üzerine çalışmalar devam etmektedir. Bu proje ile destanlarla ilgili resim, heykel ve 3D görüntüleriyle daha birçok çeşitli aktivitelerin yer alacağı büyük bir kompleks hayata geçecektir. Ayrıca Saha Yeri’nde, 2010 yılında, destanlar üzerine ilmî faaliyetlerde bulunan Oloñxo Araştırmaları Merkezi açılmıştır. Bu durum, destanlara verilen önemin ne denli büyük olduğunu ortaya koymaktadır.

Saha destan geleneğinde yer alan destanların sayısı tam olarak tespit edilmemiştir. Bununla birlikte destan sayısının oldukça fazla olduğu söylenebilir. Ergun, Yakut İlimler Akademisi arşivinde 130'dan fazla destan olduğunu kaydetmiştir (Ergun, 2013, s. 18). Yıldız ise Saha Dili, Edebiyatı ve Tarihi Bilimsel Araştırmalar Enstitüsünün verdiği envanter bilgilerine göre, folklor arşivinde 184 destan olduğunu belirtmiştir (Yıldız, 2015, s. 234). Gömeç ise destanların 150 tam metni ve 80'den fazla kısa özetinin olduğunu söylemiştir (Gömeç, 2003, s. 371). İşte bu destanlardan biri de başkahramanı kadın olan Kııs Debeliye destanıdır.

1941 yılının Haziran-Temmuz aylarında, gazeteci Stepan Konstantinoviç Dyakonov, oloñxohut Nikolay Petroviç Burnaşov'dan Kııs Debeliye isimli destanı derlemiştir. Bu destan ilk olarak SSCB’nin Sibirya şubesine bağlı Yakut Bilim Merkezi tarafından yayınlanıp arşivlenmiştir 
(Komisyon, 1993, s. 326). Dyakonov, kaydı, 21x33 cm ebatlarındaki bir deftere mor mürekkepli bir kalemle yazmıştır. Bu kayıt işlemi yaklaşık bir ay sürmüştür (Komisyon, 1993, s. 289). Sonrasında, Novosibirsk'te Pamyatniki Folklora Naradov Sibiri İ Dalnego Vostoka isimli seri içerisinde Yakutskiy Geroiçieskiy Epos Kıs Debeliye adlı çalışma yayınlanmıştır (1993). Bu çalışmanın giriş kısmını N. V. Emelyanov ve R. T. Petrov kaleme alarak destan ile ilgili 16 sayfalık bir inceleme yapmışlardır (Komisyon, 1993, s. 9-25). A. P. Reşetnikova ise destanın müziğine dair bilgilere yer verdiği "Muzıka Yakutskih Olonho" başlıklı bölümü kaleme almıştır (Komisyon, 1993, s. 26-69).

Bu çalışmada Saha Türklerinin Kııs Debeliye Buxatıır isimli destanında yer alan kahramanlar ve yer adları, iki ayrı başlık hâlinde ele alınmıştır. İlk olarak olay örgüsü anlatılarak destanın konusu hakkında bilgi verilmiştir. Akabinde kahramanlar ve yer adlarıyla ilgili önce genel bilgiler verilmiş, sonrasında kahramanın ve yerin metindeki konumu ve işlevleri üzerinde durulmuştur. Kahraman ve yer adları alfabetik olarak sıralanmış; maddelerin metinde hangi dizede geçtiği, madde sonunda dize numarası verilmek suretiyle gösterilmiştir. Kahraman ve yer adlarının metinde kaç defa geçtiği maddenin en sonunda köşeli parantez içerisinde belirtilmiştir.

\section{Olay Örgüsü}

Kuıs Debeliye, esasında Yukarı Dünya'da yaşıyor olmasına rağmen, destanda Orta Dünya'da sürgün olarak yer alır. Kııs Debeliye kadın kahramandır ve destanda olumlu bir roldedir. Orta Dünya halkının başı sıkıştığında yardımına başvurduğu önemli bir kahramandır.

Destandaki diğer bir önemli kahraman ise Çugdaan Buxatır'dır. O, Orta Dünya'dan Acına Baay Toyon ve Ecine Baay Xotun'un oğlu, destanda insanoğlunu ifade etmek için kullanılan Ayı kabilesi bahadırlarından biridir. Ülkesi Saraxana Küükenńik'in evlatları (beslemeleri) tarafından işgal edilip yağmalanınca önce kendi başına ona karşı savaşır, başarılı olamayınca Kııs Debeliye’nin yardımına başvurur.

Destanın olay örgüsündeki kötü başkahraman Saraxana Küükennik'tir. O, kötü ruhların ve bahadırların mensup olduğu Aşağı Dünya mensuplarını ifade eden Abaahı kabilesinden, meşhur Arsan Duolay'ın en küçük kızı olarak bilinir. Saraxana, Orta Dünya'da, Batı Sibirya'da çok güzel bir yer görür ve burayı beğenerek buraya sahip olmak ister. Durumu derhâl gelip babası Arsan Duolay ve annesi İ̃neli Balay'a anlatır. Ancak babası Arsan Duolay onun bu isteğini günahlarının daha çok artacağı, kendilerine rahat verilmeyeceğini söyleyerek reddeder. Bunun üzerine Saraxana, anne ve babasına Orta Dünya'da kimseye zarar vermeyeceğini, hiçbir şeye dokunmayacağını söyleyerek yemin eder. Sonra Abaahı kabilesinin yaşlıları olaya müdahil olur ve Saraxana, üç küçük kardeşiyle birlikte Orta Dünya'ya girme izni alır ve oraya yerleşir. Ancak hemen ardından ettiği yemini unutarak kardeşlerinden Yukarı Dünya'dan Kürüö Ceñke'in, Orta Dünya'dan Sabıya Baay Xotun'un ve Aşağı Dünya'dan Timir Temelekeen'in yeni doğmuş bebeklerini kaçırmalarını ister. Daha sonra bu bebekler Saraxana tarafından beslenip büyütülerek birkaç gün gibi kısa bir sürede on yaşını doldururlar. Bu çocuklar, on yaşında oldukça güçlü bir yapıya sahip olurlar. Saraxana, Yukarı Dünya'nın oğluna Kün Erili Buxatıır, 
Orta Dünya'nın oğluna da Urgunńuk Baatır adını verir. Saraxana, Yukarı ve Orta Dünya'nın çocukları da dahil olmak üzere onları açgözlü ve kötü birer karakter olarak yetiştirir. Öyle ki, Yukarı ve Orta Dünya'nın çocukları, içlerindeki hunharlık ve kötülük duygusunun etkisiyle saldırganlaşırlar. Saraxana'dan zorla Çugdaan Buxatıır'ı ve onun ülkesini öğrenirler ve Çugdaan Buxatır'ın ülkesini talan edip yağmalarlar.

Ülkesinin yağmalandığını gören Orta Dünya bahadırı Çugdaan Buxatıır, bu iki oğlanın karşısına çıkar. Onlara önce bu yaptıklarının yanlış olduğunu, esasında onların da Ayı kabilesinden olduklarını söyler ve yaptıkları hatadan vazgeçmelerini ister. Onu dinlemeyen oğlanlarla üç gün üç gece savaşan Çugdaan Buxatıır, üçüncü günün sonunda oğlanları öldüresiye döver. Bunun üzerine oğlanlar üçüncü kardeşleri olan Aşağı Dünya'nın oğlunu yardıma çağırırlar. Yapıca diğer iki oğlandan daha güçlü olan Aşağı Dünya'nın oğlu gelerek Çugdaan Buxatıır ile ölümcül bir dövüşe tutuşur. Uzun bir süre sonra yenişemeyen ikili ayrılarak daha sonra tekrar karşılaşmak üzere kavgalarına son verirler. Bu sırada Orta Dünya'nın oğlu giderken Çugdaan Buxatıı'ın kız kardeşini de kaçırır.

Evine dönen Çugdaan Buxatıır, anne ve babasından kız kardeşinin kaçırıldığını öğrenir. Anne ve babası Çugdaan Buxatıır'a, bu beladan tek başlarına kurtulamayacaklarını, daha önce hiç görmedikleri ama namını duydukları Kııs Debeliye’den yardım istemeleri gerektiğini söyler. Bunun üzerine Çugdaan Buxatır çok uzun, zorlu ve tehlikeli yolları aşarak soluğu Kııs Debeliye'nin yanında alır.

Kııs Debeliye önce Çugdaan Buxatıı'a sitem eder. Zira sürgünde olduğu süre boyunca $A y ı$ kabilesinden kimse onun yanına gelmemiştir; ilk gelen Çugdaan Buxatıır ise ondan yardım dilemektedir. Uzun uğraşlar sonucunda Çugdaan Buxatıır'ın güzel sözleriyle ikna olan Kııs Debeliye, kendilerine yardım etmesi için kız kardeşi Aan Axtalıya'yı da çağırtır. Nihayetinde Çugdaan Buxatırr, Kus Debeliye ve Aan Axtalıya bir araya gelir. Aan Axtalıya ilk önce ablasına bu olayın kendilerini ilgilendirmediğini, karışmamaları gerektiğini anlatsa da Kııs Debeliye onu ikna eder ve üçü birlikte silahlarını kuşanarak savaşın yapılacağı alana giderler.

Kııs Debeliye Aşağı Dünya'nın oğluyla, Çugdaan Buxatıır Orta Dünya'nın oğluyla, Aan Axtalıya da Yukarı Dünya'nın oğluyla eşleşerek savaşmaya başlarlar. Uzun savaş devam ederken Kııs Debeliye, kardeşi Aan Axtalıya'nın çok fazla yara aldığını fark eder ve onun derhâl savaş alanını kaçarak terk etmesini ister. Savaş alanından uzaklaşmaya çalışan Aan Axtalıya, Yukarı Dünya'nın oğlu Kün Erili’nin ani bir hareketiyle yakalanacağı sırada, Kııs Debeliye'nin hapisten serbest bıraktığı Eriede Bergen yetişir ve Aan Axtalıya'ya yardım eder. Kııs Debeliye de o sırada savaş alanında peyda olan Soluk Baatır'ın yardımıyla Aşağı Dünya'nın oğlunu yener. Kııs Debeliye, Çugdaan Buxatıır ve Eriede Bergen Buxatır'a evlerine gitmelerini söyleyerek Yukarı ve Aşağı Dünya'nın çocuklarını sırtlayarak oradan uzaklaşır.

Kııs Debeliye, sögüt ağacının dallarına astığı oğlanları döverek içlerindeki kötülüğü temizler. Oğlanlar yeniden doğmuş gibi, bugüne kadar yaşadıklarını hatırlamayan Ayı bahadırları olup çıkarlar. 
Saraxana tüm bu olanları öğrendikten sonra üç kardeşini de yanına alarak kaçar.

Kııs Debeliye, daha sonra Orta Dünya'nın oğlu ile Çugdaan Buxatır'ın kız kardeşini evlendirir. Sonrasında Kııs Debeliye, abaahılar tarafından yağmalanmış ülkenin yeniden inşası için üç gün üç gece Yukarı Dünya’nın en üst katında yaşayan, Tanrı Ürüñ Aar Toyon'a yalvarır. Ürüñ Aar Toyon bunun üzerine Kııs Debeliye'ye yardım etmesi için şaman Aytalın’’ gönderir. Şaman Aytalın’nın duasılyla ülke eski görkemli ve güzel günlerine döner.

Kııs Debeliye bu sefer güzel bir ev inşa etmek için Yukarı Dünya’nın yedinci katında yaşayan üç ilahlardan/ruhlardan biri olan Cilğa Xaan Toyon'dan yardım ister. Culğa Xaan Toyon yedi yetenekli ustasını göndererek Kııs Debeliye'nin istediği evi inşa ettirir. Bu evi de evlendirdiği Orta Dünya'nın oğlu ile Çugdaan Buxatır'’n kız kardeşine verir.

Uzun bir süre sonra, Kııs Debeliye'nin yolu Çugdaan Buxatır'ın ülkesinden geçer. Çugdaan Buxatırr, Kııs Debeliye'nin namına, ona teşekkür etmek için bir toy düzenler. Yedi gün yedi gece süren bu toyun ardından Kus Debeliye, Çugdaan Buxaatır, Ecine Baay Xatın ve Acına Baay Toyon ile vedalaşarak evine döner ve destan burada son bulur.

Kuıs Debeliye destanı, Saha destanlarının en önemli örneklerinden biridir. Bu destanın çok yönlü bir hikâyesi vardır. Ahlaki, estetik özellikleri ve epik unsurlarının çeşitliliği yönünden Saha destanlarının bütün özelliklerini bünyesinde barındırmaktadır. Kadın başkahraman Kııs Debeliye, Sahalar için önemli bir figürdür (Komisyon, 1993: 326). Kuıs Debeliye ve diğer kahramanların özellikleri şu şekildedir:

\section{Kahramanlar}

Sahaların zengin bir mitolojik dünyası vardır. Yukarı Dünya ruhların ve ilahların; Orta Dünya insanoğlunun; Aşağı Dünya abaahı olarak adlandırılan kötü ruhların yaşadığı yer olarak düşünülmektedir (Alekseyev, 2012: 3). Bu mitolojik dünyanın en belirgin izlerine destanlarda rastlanılmaktadır. Saha destanları genellikle Aşağı Dünya ruh veya bahadırlarının, Orta Dünya insanlarına veya Yukarı Dünya ruh veya bahadırlarına musallat olması neticesinde çıkan olaylar etrafında şekillenmiştir. Çalışmanın esasını teşkil eden Kııs Debeliye isimli metin de bu olayların yoğun olarak yaşandığı Saha destanlarından biridir. Bu çalışmada yer alan kahramanlar incelenirken iç içe geçmiş bulunan üç dünyanın kahramanları tasnif edilmiştir. Diğger bir ifadeyle, kahramanlar Orta Dünya Kahramanları, Yukarı Dünya Kahramanları ve Aşağı Dünya Kahramanları olmak üzere mekân bazlı bir sınıflandırmaya tabi tutulmuştur. Bu mekân sınıflandırmaları kendi içerisinde kahramanların özeliklerine göre çeşitli alt başlıklara ayrılmıştır.

\section{Yukarı Dünya Kahramanları}

Bu çalışmada ilahlar ve ruhlar aynı başlık altında ele alınmıştır. Bunun nedeni, Türkiye'deki araştırmacıların Saha ilahlarının aslında birer ruh olduğu görüşünde olmalarıdır. Bu araştırmacilardan Pervin Ergun, Sibirya Türklerinin Destanlarında İyeler isimli eserinde konuyla ilgili olarak şu yorumda bulunmuştur: "Bu alanda çalışma yapan gerek batılı ve Rus, 
gerekse yerli pek çok araştırmacı, Türk kültüründeki iyeleri “ilah” ya da "ilahe” olarak nitelendirdikleri için Türklerde çok ilahlı bir inanç sisteminin varlığına hükmedilmiştir. Bu hüküm, iyeleri ilahlar inanıcının halk hafızasında kalan hatıraları olarak görmekten kaynaklanmış olmalıdır.” (Ergun, 2019: 18). Bu yoruma karşılık Sahaların ilah ve ruhları ayrı ayrı ele aldıklarının altını çizmek gerekmektedir. Ancak Sahaların inanç sisteminin birer ürünü olan bu ilahlar ve ruhlar arasındaki ilişkiler oldukça karmaşıktır. Çalışmanın konusunun doğrudan Sahaların inanç dünyası olmaması nedeniyle tartışmalar üzerinde ayrıntılı şekilde durulmamış, Sahaların kabulleri esas alınmıştır. Tasnifte, yukarıda da belirtildiği üzere ruhlar ve ilahlar aynı başlık altında ele alınmış, ancak açıklamalarda her kahramanın özelliği, yani ruh mu yoksa ilah mı olarak nitelendirildiği ayrıca belirtilmiştir.

Destanda yer alan Yukarı Dünya kahramanları şunlardır:

\section{Başkahraman}

Kıs Debiliye Buxatıır: Destanın başkahramanıdır. Yukarı Dünya ilahları tarafından Orta Dünya'da sürgün olarak yaşar. Merhametli biridir. Çugdaan Buxatır'ın kabilesinden hiç kimsenin o güne kadar onu ziyaret etmemesine ve sadece başlarına bir bela geldiğinde kendisine müracaat edilmesine kızsa da onlara yardım etmeyi kabul eder. 1897, 2164, 2318, 2501, 2641, 2759, 3049, 3294, 3539, 3605, 3711, 3761, 3961, 3980, 4035, 4083, 4137, 4327, 4387, 4496, 4525, $4620,4652,4663,4888,4312,1816,2222,2347,2416,2604,2764,2888,2984,3193,3228,3617$, $3648,3998,4422,4609,4791,4921,4312,2823$ [45]

\section{Yardımcı Kahramanlar}

\section{ilahlar/Ruhlar}

Ayıhıt: Ev hayvanlarının ve insanoğlunun koruyucu ruhlarının veya ilahlarının genel adıdır. Saha inancın göre dokuz katlı Yukarı Dünya'nın birinci katında yaşar. Birden fazla Ayııhıt var olup her birinin farklı bir görevi vardır (Fedorov, 2011: 7-8). Ayıthtlar insanlara kadın olarak göründüğünden bütün ayııhıtların kadın olduğu düşüncesi yaygındır. Ayıhıt Xatın veya Ayııhıt Xotun (Kadın Ayıııt) adlandırmalarının da bununla ilgi olduğu düşünülebilir. Metinde Saraxana'nın, Orta Dünya'ya gitmek için anne ve babasına yalvarırken yaptığı konuşmada ve kaçırıp büyüttüğü çocuklarına yaptığı konuşmada, Kııs Debeliye’nin duasında ve çeşitli tasvirlerde adı geçer. 350, 1151, 822, 4057, 4058, 4550 [6]

Ayıhit Xatın: Bkz. Ayıhıt. 4553, 4825, 4712, 2207, 2424, 1687, 4006 [7]

Ayıhit Xotun: Bkz. Ayıhıt. 1052 [1]

Ayı Xaan: Bkz. Ürün Ayı Toyon 1870 [1]

Çımarıttar Cılğa Xaan Toyon: İnsanların kaderini belirleyen ruh veya ilahtır. Metinde Çımarıttar Cılğa Toyon ve Cılğa Toyon şeklinde de geçer. Soluk Baatır'ın konuşmasında ve Kııs Debeliye'nin dualarında adı yer alır. 3665, 4324, 4071, 4072, 4473 [5]

İeyiexsit: Ayıı ht gibi insanları, atları ve boynuzlu hayvanları koruyan dişi ruhların ve ilahların genel adıdır. Saha inancına göre dokuz katlı Yukarı Dünya'nın ikinci katında yaşar. Yedi ieyiexsit var olup her birinin farklı bir görevi vardır (Teris, 2012: 48). Metinde ismi sıkça ve 
genellikle tasvirlerde geçer. 1189, 215, 2427, 3104, 3269, 348, 4061, 4062, 448, 569, 825, 1690, $4877,2210,4009,4828,825,1690,2427,1001,39,3983,4281,4610,477,820$ [26]

İlbis: Hunharlık ve savaş ilahıdır. "İlbis Xaan diye de adlandırılır. ... Çocukları da vardır. Onlar da savaş ruhudur. Oloñxolarda bahadırın yardımcısı konumundadır. Bunlar, bahadırın ruhunu yükseltmekte ve kanlı savaşları başlatmaktadırlar. Bazı oloñxolarda İlbis'in bahadırın silahına girdiği ve silahı daha korkunç hâle getirdiği de anlatılır. Oloñxolarda savaştan önce şamanların bahadır için bunlardan yardım dileme ayini yaptığı anlatılır." (Emelyanov, 2016: 90). Metinde Kııs Debeliye'nin Kün Erili'yi kötülüklerden arındırdıktan sonra onun başına gelen olayları anlattığı pasajda adı zikredilir. 3894 [1]

İlbis Kılha: Savaş ilahı İlbis (Xaan)'ın kızı, savaş ve ölüm ilahesidir. "Saha İnanç sisteminde savaş, kıskançlık, rekabet, düşmanlık, katliam, intihar ve vakitsiz ölüm ilahesinin adıdır. Savaş tanrıçasıdır. ...zamanla babası İlbis Xaan'ın yerini aldığı için İlbis Xaan'ın adı hemen hemen unutulmuş gibidir. İlbis Kıha'ın sürekli savaş ve kan dökülmesini istemesi, oloñxoculuk geleneğinde onun abaahılar kategorisinde anılmasına sebep olmuştur. $\mathrm{O}$, bu özelliğinden dolayı üç kamburlu demir karga şeklinde bir canavar olarak tasavvur edilmektedir." (Ergun, Zakharov ve Gavriliyev, 2017: 42). Metinde Kuo Kustuktay, Obottoox Urdus Xotun, Uot Soluonńay, İlbis Xotun isimleriyle de anılır. Bahadırların savaşının anlatıldığı tasvirlerde ismi sıkça zikredilir. Bir kere de savaşın sonlarına doğru Kııs Debeliye’nin duasında adı geçer. 1595, 3376, 3154, 2118 , $3283[5]$

İlbis Xotun: Bkz. İlbis Kıhha 2045 [1]

Kuo Kustuktay: Bkz. İlbis Kııha 3158 [1]

Kün Toyon: Yukarı Dünya Ayıllarının başıdır ve Kııs Debeliye’nin dualarında adı geçer. 4049, 4463 [2]

Kürüö Ceñke: Kün Cöhögöy'ün eşidir. Metinde Saraxana Küükenńik’in emri ile kız kardeşi Itık Kıpsıydaan tarafından kaçırılan Kün Erili Buxatıır’ın babasıdır. 469, 546 [2]

Kün Cöhögöy: At ve aygırların koruyucu ilahıdır. Diğer bir adı Cösögöy Ayı Toyon'dur. Ayııhı'tan farklı olarak Cösögöy eril bir varlık sayılır. Bazen insanlara, açık renkli ve yüksek sesle kişneyen aygır suretinde görünür. Metinde Saraxana Küükenńik’in emri ile kız kardeşi Itık Kıpsıydaan tarafından kaçırılan Kün Erili Buxatıı'ın babasıdır. 1154, 468, 545 [3]

Kürüö Cöhögöy Toyon: Bkz. Kün Cöhögöy 4551 [1]

Obottoox Urdus Xotun: Bkz. İlbis Kııha 2047 [1]

Ohol Uola: Savaş ve katliamın kana susamış iyesi; savaş ilahıdır. İlbis Kııha gibi savaşanların üzerine kana susamışlık duygusu serper, tutku ve öfkeyi alevlendirir. Destanda bahadırlar savaşırken on yaşında çocuğa dönüşerek savaş alanını dokuz günde bir yıkar. 1596, 3163, 3377, 3286,2120 [5]

Uluutuyar Uluu Toyon: Yukarı Dünya'dan abaahı kabilesinin kurucusudur ve Saha mitolojisinin en karmaşık figürlerinden biridir. Olonxolarda Ürüñ Ayı'nın kardeşi, insana ateş, ikinci ruh (sur) veren, bazen onu cezalandıran; kara şamanların atası olan ilah olarak karşılaşılır. 
Puhov onu abaahıların gök tanrısı olarak niteler (Puhov, 2015: 184). Metinde bahadırların savaşı sırasında adı bir kere geçer. 3417 [1]

Uot Soluonńay: Bkz. İlbis Kııha 3165 [1]

Ürüñ Aar Toyon: Saha mitolojisindeki en büyük ilahtır. Dokuz katlı göğün dokuzuncu katında yaşar. "Şamanlara göre Ürün $A y \imath$, insanların doğrudan bakamayacakları ateşli gözlü, karşısı görünebilecek kadar şeffaf vücutludur. Yaygın görünüşe göre Ürüñ Ayı, ihtiyara ihtiyar, gence genç gözükür. ...tabiattaki her şey aslında onun görünüş değiştirmiş şeklidir. Diğer tanrıların da aynı şekilde onun görünüş değiştirmiş şekli olduğuna inanılır. İyeleri de o yaratmıştır. Ayrıca insan da onun bir parçası, bir yansımasıdır." (Yıldırım ve Kalkan, 2018: 22). Metinde Çugdaan Buxatır'ın ailesiyle yaptığı bir konuşmada, Kııs Debeliye'nin ve şaman Aytalıın'ın duasında ismi zikredilir. 1828, 4205, 4128, 4078 [4]

Üç abaahı kız: Çugdaan Buxatıır'a savaş için söylenen sürenin geldiğini, Abaahı bahadırlarının savaş alanında hazır bulunduklarını haber vermek üzere Kııs Debeliye’nin evinde birden peyda olup haber vererek ortadan kaybolan kötü ruhlardır. 2958 [1]

\section{Bahadırlar}

Aan Axtalıya: Kııs Debeliye'nin kız kardeşidir. Çugdaan Buxatır'ın Kııs Debeliye'den yardım istemesi üzerine, Kııs Debeliye tarafından çağrılır. Aan Axtalıya ilk başta Çugdaan Buxatır'a yardım etmemeleri için ablasına fikir beyan etse de ablasının ısrarları neticesinde onlara katılmaya karar verir. 2659, 2873, 2910, 3054, 3311, 3540, 3550, 3553, 3571 [9]

Kün Erili Buxatır: Yukarı Dünya'nın Ayı bahadırı ve Kün Cöhögöy ve Kürüö Ceñke’nin çocuğudur. Doğar doğmaz Saraxana Kü̈̈kenniik'in emri ile kız kardeşi Itık Kıpsıydaan tarafından kaçırılıp Saraxana'ya getirilir. Saraxana onu besleyip büyütür ve ona Kün Erili adını verir. Saraxana tarafından hırçın, açgözlü, kana susamış biri olarak yetiştirilir. Bu duygular onu Çugdaan Buxatır'ın ülkesini yağmalamaya sevk eder. Bu duygular öyle güçlüdür ki Saraxana ilk başta Çugdaan Buxatır'ın ülkesinin yağmalanmasına karşı çıktığı için diğer besleme Urgunńuk Baatır ile birlikte Saraxana'ya cebrederler. Destanın sonlarında Kııs Debeliye tarafından dövülmek suretiyle Yukarı Dünya bahadırı olduğu hatırlatılır, eski kimliğine kavuşturulur. 3310, 3581, 3592, 3790, 698, 3884, 3872 [7]

Molcuruut Buxatır: Yukarı Dünya bahadırlarındandır ve Kııs Debeliye’nin evini koruyan üç bekçiden biridir. Çugdaan Buxatıır, Kııs Debeliye’yi ziyarete geldiğinde önce bu üç oğlanla muhatap olur. Çugdaan ziyaretinin nedenini onlara anlatır ve sonrasında Molcuruut Buxatır içeriye girerek durumu Kııs Debeliye'ye anlatır. 2273, 2656, 2674, 2825 [4]

\section{Mitolojik Hayvanlar}

Key Suorun kıla: Çugdaan Buxatır'ın dönüştügü çift başlı canavar, mitolojik bir hayvandır. $2714,3062[2]$

Öksökü: Kııs Debeliye’nin dönüştüğü üç başlı mitolojik kuş, kartaldır. 3437, 408 [2] 
Ölüï Ciribiney: Mitolojik bir balıktır ve uğursuz olarak addedilir (Ergun, 2013: 201). Çugdaan Buxatıır'in savaş aletlerini tasvir ederken ismi zikredilir. 1996 [1]

Öndölüyer Öksökü kıl: Bkz. Öksökü 4641, 4959 [2]

\section{Yukarı Dünya Elçileri}

Soluk Baatır: Cılga Xaan Toyon'un haberci oğlanıdır. Metinde karnı, boğazı, omzu, sırtı kıllarla kaplı; aşağı doğru uzamış eğri burunlu; ayak tırnakları aşağı doğru uzayıp eğrilmiş; uzun ve güçlü ayaklı; geniş omuzlu, gözlerini döndüre döndüre bakan bir canavar gibi tasvir edilmiştir. Taas Eñsilgen savaş alanını ikiye yarıp bahadırlar açılan çukura düşüp savaşlarına devam ederken bu çukurun ağzında belirir ve Cılğa Xaan Toyon'un sözlerini iletir. Buna göre Kııs Debeliye’nin savaşı bitirmeden, düşmanlarını yenmeden savaş alanını kesinlikle terk etmemesi gerektiğini, aksi hâlde kutsal zıpkınını kendisine fırlatacağını söyler. 3669 [1]

\section{Diğer Kahramanlar}

Bakalaan Uus: Demircidir. Birçok olonxoda Baltalaan ismiyle yer alır. Üç dünyanın demircisi Kıday (Kıtatay, Kıtay) Bahsı'nın yardımcısı veya kardeşidir. Saha inanışına göre demircilerin kurucusu ve koruyucusudur. Metinde Çugdaan Buxatıı'ın bıçağını yapan ustalardan biri olarak yer almaktadır. 2040 [1]

Degil mañan Uustar: Yukarı Dünya’nın mitolojik ustaları; yapıların ağaç ile ilgili kısımlarını yapan ustalar, dülgerlerdir. 4411, 4347, 4353, 4381 [4]

Kırbıkaan Uus: Mitolojik demircilerden biridir. Metinde Çugdaan Buxatıır'ın bıçağını yapan ustalardan biri olarak yer almaktadır. 2042 [1]

Kökölöön Uus: Kırbukaan Uus ile aynı özelliğe ve fonksiyona sahiptir. 2041 [1]

\section{Orta Dünya Kahramanları}

Orta Dünya, insanoğlunun yaşadığı yerdir. Destanın kahramanlarından Çugdaan Buxatıır ve kabilesi burada yaşar. Destandaki olayların büyük çoğunluğu burada gerçekleşir. İncelenen destanda yer alan Orta Dünya'ya ait kahramanlar şunlardır:

\section{Başkahraman}

Çugdaan Buxatır: Ayı kabilesinin meşhur bahadırıdır. Destanda Kııs Debeliye'den sonra ikinci önemli isimdir. Ülkesinin ve kendisinin namı Saraxana'ya kadar gider. Saraxana'nın çocukları da kendilerini ispatlamak için böylesi meşhur bir bahadırı gözlerine kestirir. Çugdaan çok akıllı ve ülkesini seven bir bahadırdır. Öyle ki iki bahadıra karşı gözünü kırpmadan saldırmıştır. Abaahı bahadırlarının üstesinden gelemeyince de sırf ülkesini kurtarmak için Kııs Debeliye'ye, onlara yardım etsin diye onun önünde düz çöküp yalvarmıştır. 1176, 1283, 1338, $1608,1674,1735,1939,2189,2215,2252,2260,2357,2382,2406,2432,2443,2599,2685,2710$, $2745,2756,2819,2934,2969,3060,4617,4726,4798,4808,830,3306,1437,2900,3775,4942$, 2305, 2923 [37] 


\section{Yardımcı Kahramanlar}

\section{Bahadırlar}

Aan Daadar Buxatır: Ayı kabilesinin bahadırıdır. Destanın sonlarında ismi geçer. Destanda herhangi bir olaya dahli yoktur. Çugdaan Buxatır'ın kız kardeşi Xaançılaan Kuo ile Urgunńuk Baatır'ı evlendirip evlerini yapan Kııs Debeliye, onlardan ayrilırken Urgunńuk Baatır'a, annesinin soyundan bir çocuk doğacağını, ona Xaadıat Bergen adını vermesini, bu çocuğun ileride Aan Daadar Buxatıır ile karşılaşacağını ve kesinlikle onunla birlikte hareket etmemesi gerektiğini söyler. Böylece ilk ve son kez Aan Daadar'ın adı destanda zikredilmiş olur. 4594 [1]

Acına Baay Toyon: Ayı kabilesinin kurucusudur. Destanın başkahramanlarından Çugdaan Buxatıı'ın babasıdır. Metinde Çugdaan Buxatıır kendisini takdim ederken anne ve babasının ismini de zikrettiğinden adı sıkça geçer. 2209, 1689, 1745, 2301, 2426, 4008, 4714, 4796, 4827, 824,4939 [11]

Dokuz Oğlan: Çugdaan Buxaatır'ın Kuıs Debeliye Buxatır'’ karşılamakla görevlendirdiği, beyaz turnaya benzetilen bekâr oğlanlardır. 4630, 4646 [2]

Ecine Baay Xotun: Ayı kabilesinin kadın kurucusudur. Destanın başkahramanlarından Çugdaan Buxatır'ın annesidir. Destanda Çugdaan Buxatıır kendisini takdim ederken babası gibi annesinin adını da sıkça zikreder. 1692, 1753, 2212, 2302, 2429, 4011, 4797, 4830, 4879, 827, 4935 [11]

Eriede Bergen: Ayı kabilesi bahadırıdır. Kııs Debeliye'nin izni olmadan gizlice onun koynuna girdiği için Kus Debeliye tarafından hapsedilir ve sonradan yine Kuss Debeliye tarafından affedilir. Kuıs Debeliye, onu hapsedildiği yerden çıkarmak için Çugdaan Buxatıır' 1 yollar. Eriede Bergen, hapsolduğu yerden çıkarken Kııs Debeliye’ye sadık bir köle olacağına söz verir. Ayrıca, Aşağı Dünya bahadırlarıyla savaş yapılırken Kıııs Debeliye’nin kardeşi Aan Axtalıya, Yukarı Dünya'nın oğlu tarafından yakalanacağı sırada, Eriede Bergen yetişir ve ona yardım eder. 3777, 3609 [2]

Sabıya Baay Xotun: Ayı kabilesinin kurucusu, Saxa Saarın Toyon'un eşidir. Saraxana Küükenńik'in emri ile kız kardeşi Sayıp Kuturuk tarafından kaçırılan Urgunńuk Baatır öz annesidir. 484, 550 [2]

Saxa Saarın Toyon: Ayı kabilesinin kurucusudur. Saraxana Küükenńik'in emri ile kız kardeşi Sayıp Kuturuk tarafından kaçırılan Urgunńuk Baatır öz babasıdır. 549, 483 [2]

Simexsin Emeexsin: Hayvanlara bakan ihtiyar kadın, ataerkil ailenin kölesi olarak geçer ve birçok destanda yer alan, genellikle olumsuz bir yardımcı kahramandır. İncelenen metinde herhangi bir dahli olmamıştır, sadece Orta Dünya tasvir edilirken adı zikredilmiştir. 161 [1] 
Urgunńuk Baatır: Sabıya Baay Xotun ve Saxa Saarın Toyon'un çocuğudur. Annesi Sabıya Baay Xotun onu doğurur doğurmaz Saraxana Kü̈̈kenńik’in emri ile Saraxana'nın kız kardeşi Sayıp Kuturuk tarafından kaçırılır. Saraxana onu besleyip büyütür ve ona Urgunńuk Baatır adını verir. Saraxana tarafından tıpkı diğer besleme Kün Erili gibi hırçın, açgözlü, kana susamış biri olarak yetiştirilir. Destanın sonlarında Kııs Debeliye tarafından dövülmek suretiyle Orta Dünya bahadırı olduğu hatırlatılır, eski kimliğine kavuşturulur ve Çugdaan Buxatır'ın kız kardeşiyle evlendirilir. 4000, 4847, 3937, 1686, 3303, 3788, 4535, 4573, 706, 922 [10]

Xaadıat Bergen: Ayı kabilesi bahadırıdır. Kııs Debeliye’nin Urgunńuk Baatır’a müjdelediği, Urgunńuk Baatır'ın annesinin soyundan doğacak olan bahadırdır. 4578 [1]

Xaançılaan Kuo: Ayı kabilesi kadınıdır ve Çugdaan Buxatıı'’n kız kardeşidir. Abaahı bahadırları Çugdaan Buxatıı'ın yurdunu yağmaya geldiğinde Urgunńuk Baatır tarafından kaçırılır. Savaş bittiğinde kurtarılır ve Kııs Debeliye tarafından kötülüklerden arındırılan Urgunńuk Baatır ile evlendirilir. 1713, 1890, 2523, 4537, 4834, 4015 [6]

\section{Ruhlar}

Aan Alaxçın Xatın: Orta Dünya’nın en büyük ruhudur ve kutsal ağaç Aal Luuk Mas'ta yaşar. Olonxolarda Orta Dünya kahramanlarının baş koruyucusudur. Kahramanlara nasihat eder, tavsiyelerde bulunur ve kahramanlar yolculuğa çıkmadan önce onları kutsar. Metinde şaman Aytalın'ın duasında adı zikredilmektedir. 4235 [1]

Aan Uxxan: Ateş ruhudur. Kendisinden iyilik beklenen ruhtur. Bir diğer adı Xatan Temieriye'dir. Destanda Kıs Debeliye Buxatıır'ın savaşa giderken dua ederek yardım istediği ruh olarak yer almaktadır. 3011 [1]

Xatan Temieriye: Bkz. Aan Uxxan 3009 [1]

Cebin Kulaxay Xotun: Timir Cigisken geçidinin koruyucu ruhudur. Kııs Debeliye’nin savaşın devam ettiği sırada dua ederek yardımlarına müracaat ettiği ruhlardan biridir. 3268 [1]

Xaan Eğirgen: Kanlı dağ geçidinin ruhu, sahibidir. Kuss Debeliye’nin, savaşın devam ettiği sırada dua ederek yardımlarına müracaat ettiği ruhlardan biridir. 3264 [1]

Taas Eñsilgen: Bahadırların savaşmaları için belirlenmiş Kırpıayka isimli alanın ruhudur. Kııs Debeliye’nin savaşın devam ettiği sırada dua ederek yardımlarına müracaat ettiği ruhlardan biridir. Savaşın otuzuncu gününde Taas Eñsilgen, savaş alanını ortadan ikiye böler ve bahadırlar buraya düşerek savaşmaya devam ederler. 3209, 3475 [2]

Toyon Turantay: Kanlı dağ geçidinin sahibi olan ruhtur. Kııs Debeliye'nin savaş sırasında dua ederek yardım istediği bir başka ruhtur. 3260 [1] 
Nelber İye Xotun: İeyiexsitlerin gezdiği dağ geçidinin iyi niyetli sahibesi, ruhudur. Kııs Debeliye'nin, savaşın devam ettiği sırada dua ederek yardımlarına müracaat ettiği ruhlardan biridir. $3272[1]$

\section{Şamanlar}

Ayı Cargıl: Ayı kabilesinin kadın şamanıdır. Kuıs Debeliye’nin Urgunńuk Baatır ile Çugdaan Buxatır'ın kız kardeşi olan Xaançılaan Kuo'nun yaşayacağı yerin inşa edilmesi için Yukarı Dünya ruhlarına ettiği duada adı geçer. 4069, 4070 [2]

Aytalın: Ayı kabilesinde kadın şamandır. Kııs Debeliye’nin, Urgunńuk Baatır ile Çugdaan Buxatıı'ın kız kardeşi olan Xaançılaan Kuo'nun yaşayacağı yerin inşa edilmesi için Yukarı Dünya ruhlarına dua eder ve bunun neticesinde Aytalın gelerek onlar için dua edip tavsiyelerde bulunur. 4131, 4169, 4209 [3]

Kün Küögelcin: Gök kadın şaman ve Kün Toyon'un kızıdır. Kııs Debeliye’nin Urgunńuk Baatır ile Çugdaan Buxatır'ı kız kardeşi olan Xaançılaan Kuo'nun yaşayacağı yerin inşa edilmesi için Yukarı Dünya ruhlarına ettiği duada adı geçer .4050, 4055 [2]

Kün Küögeldin: Bkz. Kün Küögelcin 4464 [1]

\section{Aşağı Dünya Kahramanları}

Aşağı Dünya'da yaşayan abaahılarla ilgili olarak Puhov, önemli bir noktaya dikkat çeker. O, geleneksel Saha inancındaki abaahılar ile destanlardaki abaahıların birbirine karıştırılmaması gerektiğini, geleneksel inançtaki abaahıların tanrısal olduğunu, destanlardaki abaahıların ise epik bir kabileden ibaret olduğunu söyler. Diğer bir ifadeyle, destanlardaki abaahıların normal, ölümlü insan olduğunu belirtir (Puhov, 2015, s. 143). Dolayısıyla metinde geçen Aşağı Dünya'ya ait bazı kahramanlar ruhlar başlığı altında, bazıları da bahadırlar başlığı altında ele alınmıştır.

Metinde yer alan Aşağı Dünya kahramanları şunlardır:

\section{Başkahraman}

Saraxana Kü̈ükenńik: Abaahı kadını ve Arsan Duolay'ın kızıdır. Yaşadığı yerle yetinmeyip yaşamasının yasak olduğu Orta Dünya'yı gözüne kestirir. Anne ve babası ona izin vermeyince yalvarıp yakararak, orada hiç kimseye karışmayacağına, kötülük yapmayacağına dair yemin etse de Orta Dünya'ya gider gitmez verdiği sözü, ettiği yemini unutarak kötülüklerine başlar. Yeni doğmuş çocukları kaçırtıp onları hırçın, açgözlü, kana susamış biri olarak yetiştirdiği için merhametsiz biri olarak nitelendirilebilir. Büyüttüğü beslemelerin Kıss Debeliye’ye yenildiğini öğrenince Aşağı Dünya'ya kaçması dolayısıyla da korkak olarak atfedilebilir. 3960, 1237, 1789, $2258,2312,2509,251,336,3891,4099,447,557$ [12] 


\section{Yardımcı Kahramanlar}

\section{Ruhlar}

Obot Menegey: Hunharlık iyelerinden biridir. Metinde bahadırlar savaşırken on yaşında çocuğa dönüşerek savaş alanını dokuz günde bir yıkar. 3164 [1]

\section{Bahadırlar}

Arsan Duolay: Abaahı kabilesinin kurucusu ve Aşağı Dünya'nın lideridir. Ayağında prangayla doğmuş, eski bir palto giyen, rende dişli, zıpkın saçlı bir ihtiyar olarak tasvir edilir. Metinde Saraxana'dan “Arsan Duolay'ın biricik kızı” olarak söz edilmesi nedeniyle adı metinde sıkça geçer. 1236, 2256, 2310, 241, 2508, 256, 262, 303, 3443, 3889, 3956, 4096 [12]

Cebin Kulaxay: Arsan Duolay'ın kızı ve Saraxana Küükenńik'in kız kardeşidir. Saraxana'nın emri ile Aşağı Dünya'da yaşayan Ölüü Ötümextey ve Timir Temelekeen'in çocuğunu kaçırarak ablasına getirir. 379, 491 [2]

Itık Kıpsıydaan: Arsan Duolay’ın kızı ve Saraxana Kü̈̈kenńik'in kız kardeşidir. Saraxana'nın emri ile Yukarı Dünya'da yaşayan Kün Cöhögöy ve Kürüö Ceñke'nin çocuğunu kaçırarak ablasina getirir. 372,464 [2]

İñneli Balay: Abaahı kabilesinin kurucusu Arsan Duolay'ın eşi, Saraxana Küükenńik'in annesidir. Metinde Saraxana'nın Orta Dünya'ya gitmek için anne ve babasından izin istediği bölümde ismi geçer. 257, 264 [2]

Ölüï Ötümextey: Abaahı kabilesinin başı, Tınıraxtaax Dıgıydaan Böğö’nün gerçek babasıdır. $3295,3678,502,553$ [4]

Sayıp Kuturuk: Abaahı kadını ve Sarahana Küükenńik'in kız kardeşidir. Saraxana’nın emri ile Orta Dünya'da yaşayan Sabıya Baay Xotun ve Saxa Saarın Toyon'un çocuğunu kaçırarak ablasina getirir. 375,476 [2]

Tinıraxtaax Dıgıydaan Bögö: Abaahı kabilesi bahadırıdır. Ölü̈̈ Ötümextey ve Timir Temelekeen'in çocuğudur. Annesi Kürüö Ceñke onu doğurur doğurmaz ile Saraxana'nın kız kardeşi Itık Kıpsıydaan tarafından kaçırılıp Saraxana'ya getirilir. Yapı itibariyle Kün Erili ve Urgunńuk Baatır'dan daha yapılı ve güçlüdür. Saraxana Yukarı ve Orta Dünya'nın çocuklarını emzirirken sağ dizine oturtup sağ göğsüyle, Dıgıydaan Bögö’yü ise sol dizine oturtup sol göğsüyle emzirir. Açıkgözlü, kurnaz, yerinde duramayan, atik, biri olarak ve tırnaklı lakabıyla birlikte zikredilir. 1409, 2667, 2769, 3233, 3682, 710, 924, 933, 958, 3299 [10]

Timir Temelekeen: Abaahı kabilesinin kurucusu ve Ölüü Ötümextey'in eşidir. Ayrıca Tınıraxtaax Dıgıydaan Bögö’nün gerçek annesidir. 3296, 3679, 503, 554 [4] 


\section{Mitolojik Hayvanlar}

Moñoy Kı1l: Ateş çıkaran mitolojik yılandır. Saraxana'nın kardeşi Itık Kıpsıydaan'ın Yukarı Dünya'ya giderken dönüştüğü mitolojik hayvandır. 515 [1]

Ölüï Ötümex Kılla: Aşağı Dünya'nın mitolojik vahşi hayvanı. Saraxana'nın kardeşi Cebin Kulaxay’ın Aşağı Dünya'ya giderken dönüştüğü mitolojik hayvandır. 523 [1]

\section{Mekânı Belli Olmayan Kahramanlar}

Metinde geleneksel Saha inancının dışında kahramanlar da bulunmaktadır. Bunların Saha-Rus temasları neticesinde destanlara nüfuz ettiğini söylemek mümkündür. Destanın derlendiği dönem de göz önüne alındığında bu unsurların destan metninde yer alması gayet normaldir. Bu iki kahraman da Rus Ortodoks inancına ait kahramanlardır ve destandaki isim ve vazifeleri şu şekildedir:

Arxaanńal Tañara: Baş melektir. Hristiyanlık terminolojisine ait bir kavramdır. Ortodoks mitolojisinin metindeki izlerinden biridir. Destan metninin başlarında, Orta Dünya'daki Batı Sibirya adlı yer tasvir edilirken adı zikredilmektedir. Metinde tam olarak “...Arxaanńal Tañara denen, bu isimle ünlenen, kabadayı gibi yürüyen kişinin yaşayacağı yerin...” şeklinde geçer. 85 [1]

Nukuola Tañara: Hristiyanlık terminolojisine ait bir kavramdır. Ortodoks mitolojisinin metindeki izlerinden biridir. Destan metninin başlarında, Orta Dünya'daki Batı Sibirya adlı yer tasvir edilirken adı zikredilmektedir. Metinde tam olarak “...dokuz katlı, pisliği olmayan, temiz beyaz gökte, Tanrı Nikolay denilenin, hiddetiyle nam salıp yaşayacağı yerin öteki tarafında...” şeklinde geçer. 96 [1]

\section{Yer Adları}

Destanın olay örgüsü genel itibariyle Orta Dünya'da, diğer bir ifadeyle insanoğlunun halihazırda yaşamakta olduğu dünyada geçmesine rağmen, metinde bulunan yer adlarının hemen hemen hepsinin mitolojik yer adları olması dikkat çeken bir husustur. İncelenen metindeki yer adları aşağıda alfabetik sıraya göre verilmiştir.

Așağı Dünya: Saha Türkçesinde Allaraa Doydu veya kısaca Allaraa olarak adlandırılan Aşağı Dünya, kötü ruhları yaşadığına inanılan yerdir. “Alt Dünya temelinde geniş olup yukarı doğru daralır. Burada güneş ve ay farklıdır; daha sönüktür; etrafı tam olarak aydınlatmazlar. Burada dünya sürekli alaca karanlıktır. Alt Dünyanın otları ve çimenleri demirden ve dikenlidir. Örümceklerin bile battığı bela denizi olarak bilinen ateşli, yanan bataklıkları vardır. Sakinleri de tek gözlü, tek kollu, tek ayaklı çirkin yaratıklardır. Bunlar yukarıya Orta Dünya'ya çıtıklarında insanlara zarar verirler.” (Ergun, 2013: 140). Destanın baş kötü kahramanı Saraxana ve diğer Abaahı kabilesi üyeleri bu dünyada yaşarlar. 3018, 4564, 707, 521, 524, 3953, $1235,233,3496,3658,4745,492,552[13]$

Batı Sibirya (Arğaa Sibiir): Orta Dünya'da yer alan bir ülkedir. Bu kavramın, olonxolarda Sibirya adının etkisiyle oluştuğu düşünülür. Bununla birlikte Sibiir kelimesi olonxolardaki sir 
“toprak, ülke” kelimesiyle eş anlamlı olup günümüzdeki coğrafi adlandırma ile aynı değildir. Metinde Batı Sibirya Sahaların yaşadığı yeri içine alan bölgenin adıdır. Yeryüzünün yarısını kapladığı tasavvur edilir. Metinde mitolojik olmayan tek yer adıdır. 110, 113, 1234, 1786, 2507, 2892, 3944, 4091, 4212, 4335, 4835, 2327, 4119, 4134, 4623 [15]

Buolak Xaya: Buolak dağı. Bahadırların savaşması için tahsis edilmiş alandır. Metinde bahadırın savaşı burada gerçekleşir. Çugdaan Buxatıır, Abaahı bahadırlarıyla yaptığı ilk mücadeleden mağlup çıkınca, ikinci kez karşılaşmak üzere Abaahı bahadarlarına Buolak Xaya' da karşılaşmayı teklif eder. 1649, 3182, 3493 [3]

Cölörü Xaan: Aşağı Dünya'dan Orta Dünya’ya açılan geçitlerden biridir. Saraxana Küükenńik ve kız kardeşleri Itık Kıpsıydaan, Sayıp Kuturuk ile Cebin Kulaxay Aşağı Dünya'dan Orta Dünya'ya giderken bu geçitleri kullanır. 417 [1]

Çuguya Xaan: Aşağı Dünya'dan Orta Dünya’ya açılan geçitlerden biridir. Bkz. Cölörü Xaan $411[1]$

Çağıya Xaan: Aşağı Dünya'dan Orta Dünya'ya açılan geçitlerden bir diğeridir. Bkz. Cölörü Xaan 413 [1]

Degie: Bkz. Yana (Caañı) 3630 [1]

Delbirge Xaan: Bir dağ geçidi. Muhtemelen Orta Dünya'da; adak olarak yele ve bez parçalarının bağl1 bulunduğu bir yerdir. 3106, 3271 [2]

Kirpaayka: Bkz. Kırpıayka 1651, 3516 [2]

Kırpıayka: Kahramanların savaşları için belirlenmiş alandır. Hakkında kesin bir bilgi yoktur. Metne göre de ya Buolak Xaya ile aynı ya da Buolak Xaya'nın hemen yanında bir yer olmalıdır. Çünkü ismi Buolak Xaya ile birlikte zikredilir. 3183, 3208, 3462 [3]

Kileye Xaan: Aşağı Dünya'dan Orta Dünya'ya açılan geçitlerden başka biridir. Bkz. Cölörü Xaan 409 [1]

Kimeen İmeen doydu: Kahramanın okunu hazırlamak için gerekli olan ağaç kökünün bulunduğu epik yerdir. Birçok olonxoda kahramanın okunu tasvir ederken Tumaan-İmeen ve Hamaan-İmeen adları ile birlikte kullanıldı̆̆ı görülür. Metinde Çugdaan Buxatıır’n silahları tasvir edilirken kullanır. 1994 [1]

Orta Dünya: Saha Türkçesinde Orto Doydu olarak adlandırılan Orta Dünya, insanoğlunun ve orman, dağ, akarsu, geçit vb. doğa unsurlarının ruhlarının yaşamını sürdürdüğü yerdir. Destanın esas konusu bu mekânda gerçekleşmiştir. Orta Dünya'nın oldukça güzel ve canlı bir yer olması dolayısıyla, Aşağı Dünya ruhlarından ve destanın başkahramanlarından Saraxana 
Kü̈̈kenniik'in burayı ele geçirmek istemesi ile destan başlar. Devamındaki olaylar ise destanın ana konusunu oluşturur. 363, 2153, 313, 3455, 4570, 517, 548, 781, 2692, 1431, 3025, 4333, 4560, $1401,1684,3301,3786,3935,4533,4845,703,722,920,2913$ [24]

Suordaax Suksulla Xaan: Kanlı dağ geçididir. Metinde Toyon Turantay'ın ruhu olduğu geçittir. Metinde, Kııs Debeliye’nin, Kırpıayka'nın ruhu olan Taas Eñsilgen'e yalvardığı konuşmada ismi zikredilir.3259 [1]

Timir Cigisken: Dağ geçididir. Metinde Cebin Kulaxay Xotun'un ruhu olduğu geçittir. Kuıs Debeliye'nin, Kırpıayka'nın ruhu olan Taas Eñsilgen'e yalvardığı konuşmada ismi zikredilir. $3267[1]$

Tumaan İmeen doydu: Bkz. Kimeen imeen doydu 1992 [1]

Unaarıtta Ebe Xotun: Orta Dünya'da, insanoğlunun yaşadığı çok güzel bir doğaya sahip yerin özel adıdır. Metinde “...Batı Sibirya’nın yüksek yeri, meşhur alanı, arkası görünmez, karşısı bilinmez Unaarıtta Ebe Xotun...” şeklinde tasavvur edilir. 131, 3949, 3982, 422, 137, 4288 [6]

Uot Kudulu: Mitolojik ateş denizidir. Aşağı Dünya'da yer almaktadır. Metinde, bahadırların savaşı devam ederken ortaya çıkan Kırpıayka'nın ruhu olan Taas Eñsilgen, bahadırları bu denizin hemen sağındaki yere kovar. 3506 [1]

Üöden: Bkz. Ütügen 3651, 3975, 4222, 1597, 2666, 3229, 3498, 500 [8]

Ütügen: Cehennem ve Aşağı Dünya anlamlarına gelmektedir. Metinde ekseriya cehennem anlamında kullanılır. Çünkü Aşağı Dünya ifade edilmek istendiğinde Allaraa veya Allaraa Doydu terimleri kullanılmıştır. 3703, 4224, 3976, 3430 [4]

Yana (Caañı): Bir ırmağın adıdır. Soluk Baatır’ın tırnaklarını tasvir ederken kullanılır. Soluk Baatır'in tırnakları burada Yana tırpanına benzetilir. 3628 [1]

Yukarı Dünya: Saha Türkçesinde Ü̈̆hee Doydu olarak adlandırılan Yukarı Dünya; ruhların, ilahların ve Yukarı Dünya bahadırlarının yaşadığı yerdir. Doğu ve Güney göğün bu dünyada olduğu tasavvur edilir. Doğu gökte dokuz kat vardır ve bu katlarda destan metinde yer alan ilahlar, ruhlar yer alır (Yıldırım ve Kalkan, 2018, s. 6). 4562, 2272, 2673, 2825, 3309, 3580, 3612, 3789, 3871, 3883, 641, 696, 1245 [13]

Xaan Çuguya: Bkz. Çă̆ıya Xaan 3120, 3263, 3796 [3]

Xamaan İmeen doydu: Bkz. Kimeen İmeen doydu 1990, 3482 [2]

Xoñoroy Cuorsun: Dar, uzun ve çıplak tepedir. Metinde Kün Erili ve Urgunńuk Baatır Çugdaan Buxatır'ın yurdunu yağmaya geldiklerinde, keşif için önce bu tepeye çıkıp etrafı seyrederler. Bunun haricinde bazı tasvirlerde de bu tepenin ismi zikredilir. 1055, 1063, 1543, 3179 [3]

\section{Sonuç}

Destan, milletlerin hafızası olan değerli bir anlatı türüdür. Toplumun geçmiş dönemlerden günümüze kadarki sürecinde halkın hafızasında kalan izlerini, yaşanmışlıklarını, gelenek, görenek ve inanç sistemini yansıtması, ayrıca insanların hayal dünyalarını, umut ve beklentilerini yansıtması sebebiyle destanlar önemlidir. Sahalar, zengin bir destan külliyatına 
sahiptir. Yazıya geç geçmeleri nedeniyle Sahaların tarihi hakkında çok fazla yazılı kaynak yoktur. Tarihî araştırmalarda içerik olarak tarihsel bilgi barındırması dolayısıyla oldukça değerli bir bilgi kaynağı durumunda olan destanlar, Saha kültüründe önemli bir yer teşkil etmektedir. Geleneksel Saha inanç sisteminin tüm izlerini bünyesinde bulunduran destanlar, gerek kahramanların gerekse olayların geçtiği yerlerin mitolojik özellikleri dolayısıyla Türk destan geleneğinde müstesna bir konuma sahiptirler.

İncelenen metinde, Orta Dünya'dan yirmi üç kahraman, yüz bir defa; Yukarı Dünya'dan yirmi dört kahraman, yüz elli beş defa; Aşağı Dünya'dan on iki kahraman, kırk üç defa ve mekânı belli olmayanlar olarak değerlendirilen Hristiyan Ortodoks inancının metindeki izleri olarak tespit edilen iki kahraman da iki defa zikredilmiştir. Toplamda altmış bir kahraman, üç yüz bir defa zikredilmiştir. Metnin genelinde Orta Dünya'dan olan on beş insanoğlu haricinde, geriye kalan kırk altı kahraman mitolojik özellik taşımaktadır. Kahramanlar ve bunların isimlerinin sıkça tekrarlanması, mitolojik türde olan destanın bu açıdan zenginliğini göstermektedir.

İncelenen metinde tespit edilen yer adı sayısı yirmi beştir. Bu yirmi beş yer adı toplamda doksan yedi defa metinde zikredilmiştir. Batı Sibirya (Arğaa Sibiir) haricinde geriye kalan isimler Saha destanlarında yer alan mitolojik yer adlarıdır. Bu özelliğiyle de kahramanlarda olduğu gibi yerle ilgili mitolojinin de destana yaygın bir şekilde yansıdığını söylemek mümkündür.

Yapılan inceleme neticesinde elde ettiğimiz veriler, Saha Türklerinin destan dünyasında kurguladıkları şahısların mekânlara göre uygun bir şekilde yerleştirildiğini, her mekânın kendine has şahıs kadrosuyla oluşturulduğunu, anlatıcının destan metnini söylerken şahıs ve yer adlarını rastgele değil, kompozisyon bütünlügünde belirli bir mantık ve inanç sistemine bağlı kalarak yarattığını açıkça göstermektedir.

\section{Kaynakça}

Alekseyev, A. (2012). Ayı iteğelin tuhunan, Cokuuskay: Biçik.

Emelyanov, N. V. (2016). Soy Ataları hakkında olongho konuları, Çev.: Metin Ergun, Konya: Kömen.

Ergun, M. (2013). Yakut destan geleneği ve er sogotoh, Ankara: TDK.

Ergun, M., Zakharov, T., ve Gavriliyev. Ç. (2017). Sakha Kahramanlık destanı ehe khara atlı eles bootur, Konya: Kömen.

Ergun, P. (2019). Sibirya Türklerinin destanlarında iyeler, Konya: Kömen.

Fedorov, A.S. (2011). Öbüge siere-tuoma, Cokuuskay: Biçik.

Gömeç, S. (2003). Türk Cumhuriyetleri ve toplulukları tarihi, Ankara: Akçağ.

Komisyon. (1993). Yakutskiy geoiçeskiy epos kııs debeliye, Novosibirsk: NAUKA. 
Puhov, İ. V. (2015). Yakut kahramanlı destanı olonho genel tipler, Çev.: Metin Ergun, Konya: Kömen.

Teris (2012). İteğel Tılcıta, Cokuuskay: Biçik.

Yıldırım, H., Kalkan, N. (2018). Saha Türklerinde Tanrı öğretisi şamanizm, Ankara: Gazi Kitabevi.

Yıldız, N. (2015). Türk dünyası destancılık geleneği ve destanlar, Ankara: Akçağ. 